\title{
Editorial
}

\section{Editorial: Getting Evidence Into Practice - or Not: The Case of Viscosupplementation}

\author{
Seth S. Leopold MD
}

N ot news in 2012: "Viscosupplementation Largely Ineffective" [26].

News in 2015 and beyond: "Viscosupplementation Market Value to Exceed \$2.6 Billion by 2021, says GlobalData" [5].

We should be able to say three things about any treatment we use: It is effective, it is safe, and it is worth the cost. Unfortunately, we cannot always achieve this standard in orthopaedic surgery, just as elsewhere in medicine. Some conditions surgeons treat are too

The author certifies that he, or any members of his immediate family, has no commercial associations (eg, consultancies, stock ownership, equity interest, patent/licensing arrangements, etc) that might pose a conflict of interest in connection with the submitted article.

All ICMJE Conflict of Interest Forms for authors and Clinical Orthopaedics and Related Research ${ }^{\mathbb{R}}$ editors and board members are on file with the publication and can be viewed on request.

The opinions expressed are those of the writers, and do not reflect the opinion or policy of $C O R R^{\mathbb{R}}$ or The Association of Bone and Joint Surgeons ${ }^{\circledR}$.

S. S. Leopold MD ( $\square)$

Clinical Orthopaedics and Related

Research®, Philadelphia, PA 19103,

USA

e-mail: sleopold@clinorthop.org rare for us to accumulate solid data about how they behave, and some procedures too-uncommonly indicated for us to gather high-quality evidence about their efficacies. In addition, some interventions used by surgeons looked promising early on, but later fell from favor as better research found them to be less-effective than initially imagined, or even unsafe. Thermal capsullorhaphy [12], certain arthroplasty bearing-surface "improvements" old [23] and new [10], and use of bone morphogenic protein in certain spinal fusions [6] all come to mind here.

Surgeons who follow the evidence should relegate injectable viscosupplements (hyaluronic acid products) to the list of abandoned treatments. Several comprehensive analyses agree that they either are minimally effective or ineffective $[9,14,20]$. They probably are safe, though their use carries some risk [20]. To the degree that they are not effective [9, 14, 20], it is hard to make a case for their value [21].

Yet despite going only one for three on the efficacy-safety-value scorecard, the market for injectable viscosupplements continues to grow $[3,5]$.

I know there are many proponents of these treatments in the orthopaedic community; however, the observations about viscosupplementation's inefficacy are not mine alone. Well-done reviews and meta-analyses recommending against the use of this treatment have appeared in The New England Journal of Medicine [7] and Annals of Internal Medicine [20]; The Osteoarthritis Research Society International's (OARSI) guidelines for the non-surgical management of knee osteoarthritis listed viscosupplementation among the treatments of "uncertain appropriateness," alongside avocado soybean unsaponfiables, chondroitin, diacerein, glucosamine, rosehip, transcutaneous electrical nerve stimulation, and ultrasound [14]. The American Academy of Orthopaedic Surgeons released a clinical practice guideline in 2013 based on an analysis of the best-available research, which concluded, "We cannot recommend using hyaluronic acid for patients with symptomatic osteoarthritis of the knee" [9]. The Academy rated that recommendation as "strong," meaning it was based on high-quality supporting evidence; that rating carries the following implication: "Practitioners should follow a Strong [emphasis theirs] recommendation unless a clear and compelling rationale for an alternative approach is present." 
The recent projection about viscosupplementation's financial growth [5] came out some 2 years after that practice guideline. No compelling rationale has emerged during that time to justify the use of these products, let alone the increased use of them. Thoughtful critiques and one major new analysis have indeed been published since then $[1,2,13]$, but these cannot escape the reality of the primary-source data upon which the Academy's guideline (as well as OARSI's) rest: If viscosupplementation offers any benefit to patients, it is small and of questionable clinical importance. In addition, Jacobs et al. [8] have identified factual and analytical errors in both of those Level $\mathrm{V}$ critiques [1, 13] of the Academy's guideline.

Viscosupplementation is not the only treatment surgeons continue to use despite substantial evidence of inefficacy or risk. In fact, more money probably is spent on arthroscopy for degenerative meniscus tears [22], and substantial geographic differences in the frequency of spinal procedures strongly suggests that they are overused, exposing more patients to surgical risk than may be justifiable [4]. But if there is another example of a musculoskeletal intervention performed principally by orthopaedic surgeons [21] that boasts a growing market despite high-quality reviews, dozens of randomized trials, methodologically sound meta-analyses, and a robust clinical practice guideline from the Academy recommending against its use, I am not aware of it.

Why might this be so? One reason might be that surgeons have relatively few effective nonsurgical alternatives that help patients with their joint pain, and-being members of a helping profession-we find this frustrating. However, our lack of effective nonsurgical treatments cannot justify the use of an ineffective one, and it must not be used to justify surgery unless surgery is indicated. Some patients will have pain that persists despite well-tested nonsurgical treatments, but not enough to warrant major joint surgery; others may not fit the biopsychosocial profile that supports a decision to perform elective arthroplasty. The answer to this is not to use a treatment like viscosupplementation that studies suggest is ineffective, nor to take a chance on surgery when it seems ill-considered to do so, but rather to explain to patients that there are some problems for which we have no effective treatments, and to help those patients adjust and adapt.

Another reason that viscosupplementation remains in common use is a common perception that it works. There may be many explanations for this perception, but it seems most likely to be the result of transfer bias - the satisfied patients return, and the dissatisfied ones move on to get further care elsewhere, leaving the surgeon feeling more effective than (s)he should. Selection bias and assessment bias (failing to use validated outcomes tools) - both of which are present in day-to-day practice experience-also tend to inflate the apparent benefits of the treatments we use. The earlier-noted reviews, metaanalyses, and practice guidelines evaluated high-quality randomized trials went to lengths to minimize these three sources of bias, and when they did so, the apparent benefits of the treatment were found to be much smaller (or were absent entirely), compared to earlier and less-robust analyses. There are many treatments for arthritis that some providers' experiences and anecdotal evidence might support-copper bracelets, magnets, and others-but most physicians would not accept anecdotes or experiences as justification to use such treatments when evidence has found them to be ineffective $[18,19]$. If the evidence against viscosupplementation's efficacy is robust, as appears to be the case, should we not likewise abandon this treatment, regardless of anecdotes and experiences?

But the growing market for these products suggest that the opposite is happening, and this raises many questions about evidence, practice, and 


\section{Editorial}

perhaps even the role of journals in this process. We know that evidence diffuses into practice both slowly and inconsistently [11, 25]; could the observations about increased viscosupplementation usage therefore simply represent the usual delay between discovery and implementation of evidence into clinical care? After all, the guidelines recommending against viscosupplementation are not the only ones that have yet to make the leap from paper to practice [16], and as professionals, surgeons have a reasonable aversion to "cookbook" medicine [24]. In the case of viscosupplements, though, the evidence seems too robust to ignore. We know that marketing, both to physicians and to patients, influences practice $[15,17]$. Is the case of viscosupplementation simply another instance of advertising outmuscling science? One hopes that the ongoing use-and seemingly increasing market size-of viscosupplements is not a function of self-interest on the part of the physicians using these products, although their use remains remunerative to physicians and practices. Are journals failing to get the right evidence in front of the right providers in ways they can use it? If so, how might we do better?

Share your thoughts with us about how evidence influences practice-or fails to do so-in a letter to the editor to eic@clinorthop.org.

\section{References}

1. Bannuru RR, Vaysbrot EE, McIntyre LF. Did the American Academy of Orthopaedic Surgeons osteoarthritis guidelines miss the mark? Arthroscopy. 2014;30:86-89.

2. Campbell KA, Erickson BJ, Saltzman BM, Mascarenhas R, Bach BR, Cole BJ, Verma NN. Is local viscosupplementation injection clinically superior to other therapies in the treatment of osteoarthritis of the knee: A systematic review of overlapping metaanalyses. Arthroscopy. 2015;31:20362045.e14.

3. Decision Resources Group. Global market for hyaluronic acid viscosupplementation to reach $\$ 2.8$ billion by 2022. Available at http://www. prnewswire.com/news-releases/globalmarket-for-hyaluronic-acid-viscosupplementation-to-reach-28-billion-by2022-242396361.html. Accessed on October 23, 2015.

4. Deyo RA, Mirza SK. The case for restraint in spinal surgery: Does quality management have a role to play? Eur Spine J. 2009;18(Suppl 3):331-337.

5. GlobalData. Viscosupplementation market value to exceed $\$ 2.6$ billion by 2021, says GlobalData. Available at http://healthcare.globaldata.com/ media-center/press-releases/medicaldevices/viscosupplementation-marketvalue-to-exceed-26-billion-by-2021says-globaldata. Accessed September $25,2015$.

6. Goode AP, Richardson WJ, Schectman RM, Carey TS. Complications, revision fusions, readmissions, and utilization over a 1-year period after bone morphogenetic protein use during primary cervical spine fusions. Spine J. 2014;14:2051-2059.

7. Hunter DJ. Viscosupplementation for osteoarthritis of the knee. $N$ Engl J Med. 2015;372:1040-1047.

8. Jacobs JJ, Jevsevar DS, Brown GA, Cummins DS. AAOS osteoarthritis guideline: Transparency and credibility. Arthroscopy. 2014:30;656664.

9. Jevsevar DS, Brown GA, Jones DL, Matzkin EG, Manner PA, Mooar P, Schousboe JT, Stovitz S, Sanders JO, Bozic KJ, Goldberg MJ, Martin WR 3rd, Cummins DS, Donnelly P, Woznica A, Gross L; American Academy of Orthopaedic Surgeons. The American Academy of Orthopaedic Surgeons evidence-based guideline on: Treatment of osteo arthritis of the knee, 2nd edition. Available at http://www.aaos.org/research/guidelines/TreatmentofOsteo arthritisoftheKneeGuideline.pdf. Accessed October 23, 2015.

10. Lainiala O, Reito A, Elo P, Pajamäki J, Puolakka T, Eskelinen A. Revision of metal-on-metal hip prostheses results in marked reduction of blood cobalt and chromium ion concentrations. Clin Orthop Relat Res. 2015; 473:2305-2313.

11. Lenfant C. Clinical research to clinical practice - lost in translation? N Engl J Med. 2003;349:868-874.

12. Longo UG, Rizzello G, Loppini M, Locher J, Buchmann S, Maffulli N, Denaro V. Multidirectional instability of the shoulder: A systematic review. [Published online ahead of print July 21, 2015]. Arthroscopy. DOI: 10.1016/j.arthro.2015.06.006. 


\section{Editorial}

13. Lubowitz JH, Provencher MT, Poehling GG. Congratulations and condemnations: Level I evidence prize for femoral tunnel position in ACL reconstruction, and AAOS clinical practice guidelines miss the mark - again. Arthroscopy. 2014;30:2-5.

14. McAlindon TE, Bannuru RR, Sullivan MC, Arden NK, Berenbaum F, Bierma-Zeinstra SM, Hawker GA, Henrotin Y, Hunter DJ, Kawaguchi H, Kwoh K, Lohmander S, Rannou F, Roos EM, Underwood M. OARSI Guidelines for the non-surgical management of knee osteoarthritis. Osteoarth Cartilage. 2014;22:363368.

15. McKinlay JB, Trachtenberg F, Marceau LD, Katz JN, Fischer MA. Effects of patient medication requests on physician prescribing behavior: Results of a factorial experiment. Med Care. 2014;52:294-299.

16. Oetgen ME, Blatz AM, Matthews A. Impact of clinical practice guideline on the treatment of pediatric femoral fractures in a pediatric hospital. J Bone Joint Surg Am. 2015;97:1641-1646.

17. Pew Charitable Trusts. Fact sheet persuading the prescribers: Pharmaceutical industry marketing and its influence on physicians and patients.
Available at http://www.pewtrusts. org/en/research-and-analysis/factsheets/2013/11/11/persuading-theprescribers-pharmaceutical-industrymarketing-and-its-influence-on-physicians-and-patients. Accessed October 23, 2015.

18. Richmond SJ, Brown SR, Campion PD, Porter AJ, Moffett JA, Jackson DA, Featherstone VA, Taylor AJ. Therapeutic effects of magnetic and copper bracelets in osteoarthritis: A randomised placebo-controlled crossover trial. Complement Ther Med. 2009;17:249-256.

19. Richmond SJ, Gunadasa S, Bland M, Macpherson H. Copper bracelets and magnetic wrist straps for rheumatoid arthritis-analgesic and anti-inflammatory effects: A randomised doubleblind placebo controlled crossover trial. PLoS One. 2013;8:e71529.

20. Rutjes AW, Jüni $P$, da Costa BR, Trelle S, Nüesch E, Reichenbach S. Viscosupplementation for osteoarthritis of the knee: A systematic review and meta-analysis. Ann Intern Med. 2012;157:180-191.

21. Schmajuk G, Bozic KJ, Yazdany J. Using Medicare data to understand low-value health care: The case of intra-articular hyaluronic acid injec- tions. JAMA Intern Med. 2014;174: 1702-1704.

22. Sihvonen R, Paavola M, Malmivaara A, Itälä A, Joukainen A, Nurmi H, Kalske J, Järvinen TLN for the Finnish degenerative meniscal lesion study (FIDELITY) group. $N$ Engl $J$ Med. 2013;369:2515-2524.

23. Silverton $\mathrm{C}$, Rosenberg AO, Barden RM, Sheinkop MB, Galante JO. The prosthesis-bone interface adjacent to tibial components inserted without cement. Clinical and radiographic follow-up at nine to twelve years. J Bone Joint Surg Am. 1996;78:340-347.

24. Swiontkowski M. JBJS editor's choice - clinical practice guidelines: What good are they? Available at http://orthobuzz.jbjs.org/2015/10/ 21/jbjs-editors-choice-clinical-practice-guidelines-what-good-are-they/. Accessed on October 23, 2015.

25. Tejwani NC, Immerman I. Myths and legends in orthopaedic practice: Are we all guilty? Clin Orthop Relat Res. 2008:466:2861-2872.

26. Wilhelm CB. Viscosupplementation largely ineffective. Available at http:// www.painfreelivinglife.com/blog/viscosupplementation-largely-ineffective/. Accessed September 25, 2015. 